\title{
Relationship between air diffusivity and permeability coefficients of cementitious materials
}

\author{
Yuya Sakai ${ }^{1 *}$ \\ ${ }^{1}$ Institute of Industrial Science, The University of Tokyo, Japan
}

Received: 05 June 2020 / Accepted: 28 August 2020 / Published online: 04 September 2020

C The Author(s) 2020. This article is published with open access and licensed under a Creative Commons Attribution 4.0 International License.

\begin{abstract}
In this study, a straight circular tube was used to represent a capillary pore and theoretically investigate the relationship between the diffusion and air permeability coefficients. First, an equation to correlate the air diffusivity and permeability in a straight circular tube was derived. Then, data were collected from previous studies in which both the air diffusivity and permeability were measured, and the applicability of the derived equation to cementitious materials was verified. Although a correction factor was not used, the two datasets exhibited good quantitative agreement. This indicates that the derived equation can be applied to cementitious materials, including concrete, and the measured air diffusivity can be converted into concrete permeability (and vice versa) using the derived equation.
\end{abstract}

Keywords: Air permeability; Diffusion; Concrete; Mortar; Cement paste

\section{Introduction}

Evaluation of concrete durability is becoming increasingly important for rational design and maintenance. Carbon dioxide and oxygen are important deterioration factors for reinforced-concrete structures, as they cause carbonation of the concrete and corrosion of the reinforcement [1]. Therefore, appropriate evaluation of the resistance to gas penetration should be performed to assess the potential or durability of concrete structures. Generally, air diffusivity tests [2,3] or air permeability tests [4-6] are conducted to evaluate the air penetration in concrete. The driving force in the former case is the concentration gradient of the relevant gas, whereas that in the latter case is the pressure gradient. The conditions in a diffusivity test are closer to the real conditions of oxygen and carbon-dioxide penetration in concrete. However, the experimental setup of the diffusivity test is complex because the pressures on the two flat surfaces of the sample plate should be kept equal, and the gas concentration should be monitored during the test.

In air permeability testing, the volume of air penetrating the concrete due to a pressure gradient is determined by measuring the volume of air penetration or air pressure. This test can be conducted using a relatively simple setup. Recently, devices for in situ investigation of the air permeability have been developed [7-13]. The author has

\footnotetext{
* Corresponding author: Yuya Sakai, Email: ysakai@iis.u-tokyo.ac.jp
}

conducted air permeability tests on actual structures in Japan and overseas [14, 15] (Fig. 1). However, it is unclear whether the actual penetration of oxygen or carbon dioxide due to diffusion can be evaluated using the air permeability test. The correlation between the air diffusivity and permeability coefficients has been reported [16-19], but no method for converting the air permeability into the diffusivity has been established. Once the relationship between the air diffusivity and the permeability is established, the penetration of carbon dioxide and oxygen can be estimated according to the air permeability measured with a simple experimental setup or even non-destructive testing.

The author has investigated the relationships between the various pore-structure indicators of cementitious materials and ion, air, and water transfer. Among the indicators, the total porosity had the strongest correlation with chloride-ion diffusion [20], and the threshold pore diameter obtained using the method proposed by the author had the strongest correlation with air and water permeabilities [21,22] and air diffusion [23]. These relationships indicated that air permeability can be empirically converted into the air diffusion (and vice versa) by using the threshold pore diameter as an indicator, but the results may have low accuracy. 

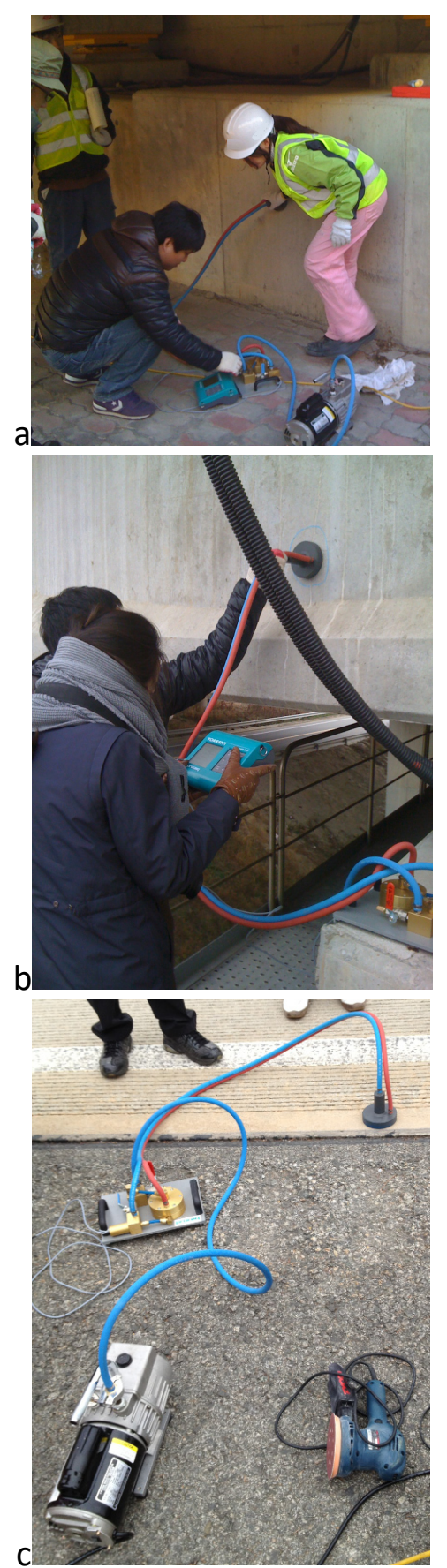

Figure 1. Onsite air permeability measurement using the doublechamber method [7]

In this study, a straight circular tube was used to represent a capillary pore for theoretically investigating the relationship between the diffusion and air permeability coefficients. Then, data were collected from studies in which both the diffusion and permeability coefficients of concrete, mortar, and paste were measured, and the reported and calculated values were compared to confirm that the obtained relationship is applicable to actual cementitious materials with a complex pore structure.

\section{Derivation of theoretical equation}

Airflows can be divided into two main types: molecular and viscous. In a molecular flow, collisions between air molecules and the wall are dominant and occur in a small space or depressurised condition. In a viscous flow, collisions between air molecules are dominant and occur in a large space or pressurised condition. The dominant flow can be determined by examining the Knudsen number, which is calculated as follows [24]:

$$
K_{n}=\frac{\lambda}{L_{s}}
$$

where $\lambda$ represents the mean free path $(m)$, which is the average distance travelled by a gas molecule between successive impacts, and $L_{s}$ represents the characteristic length $(\mathrm{m})$, which corresponds to the diameter of the pipe or pore. $\lambda$ can be calculated as follows [25]:

$$
\lambda=\frac{1}{\sqrt{2}} \times \frac{k_{B} T}{\pi P d^{2}},
$$

where $k_{B}$ is the Boltzmann constant $\left(1.3807 \times 10^{-23} \mathrm{~N} \cdot \mathrm{m} / \mathrm{K}\right), T$ represents the temperature $(\mathrm{K}), P$ represents the pressure $(\mathrm{Pa})$, and $d$ represents the molecular diameter $(\mathrm{m})$.

In general, a flow with $K_{n}<0.01$ is considered to be viscous, $K_{n}$ $>1$ is considered to be molecular, and $0.01 \leq K_{n} \leq 1$ is considered to be transient $[24,26]$. When the molecular flow is dominant, the molecular diffusion coefficient through the tube $D_{m}$ is expressed as follows [27]:

$$
D_{m}={\frac{C_{m} l}{A+\frac{1}{4} \beta H s \bar{v} \tau}}^{\prime}
$$

where $C_{m}$ represents the conductance in the molecular flow $\left(\mathrm{m}^{3} / \mathrm{s}\right)$, I represents the distance between two points $(\mathrm{m}), A$ represents the inner cross-sectional area of the circular tube $\left(\mathrm{m}^{2}\right), 6$ represents the coefficient of the surface roughness, $H$ represents the tube perimeter $(\mathrm{m}), s$ is a constant $(<1 ; 1-s$ represents the fraction of specular reflected molecules), $\bar{v}$ represents the root-mean-square velocity of a gas molecule $(\mathrm{m} / \mathrm{s})$, and $\tau$ represents the mean sojourn time of molecules adsorbed on the tube surface.

The second term in the denominator of Eq. (3) can be ignored because air consists mostly of nitrogen, which has a very short $\tau$ of $10^{-12} \mathrm{~s}$, and the $b$ and $s$ of concrete have not been established quantitatively. The effect of this term was estimated in [28] and was not large for $D_{m^{*}}>10^{-5} \mathrm{~m}^{2} / \mathrm{s}$; however, $D_{m^{*}}$ and the $D_{m}$ used in the present study cannot be directly compared, as $D_{m}$ corresponds to a specific circular tube, whereas $D_{m^{*}}$ is the measured value for specimens made of cementitious materials.

For a straight circular tube, $C_{m}$ is expressed as follows $[25,27]$ :

$$
C_{m}=\frac{2 \pi r^{3} \bar{v}}{3 l},
$$

where $r$ represents the tube radius $(m)$. The air permeability coefficient when the molecular flow is dominant, i.e. $k_{m}\left(\mathrm{~m}^{2}\right)$, is expressed as follows [29]: 


$$
k_{m}=\frac{2 \bar{v} \mu}{3 P_{m}} r,
$$

where $\mu$ represents the viscosity of the air (Pa.s), and $P_{m}$ represents the mean pressure of two points $(\mathrm{Pa})$. By combining Eqs. (3)-(5), the relationship between the air diffusion and the permeability coefficients when the molecular flow is dominant is obtained as follows:

$$
D_{m}=\frac{P_{m}}{\mu} k_{m} .
$$

In contrast, in a large space where the viscous flow is dominant, the diffusion coefficient $D_{v}$ is equal to that of the bulk, where the effect of the boundary is negligible. In this case, the diffusion coefficient is expressed as follows:

$$
D_{v}=D_{0} \text {, }
$$

where $D_{0}$ represents the bulk diffusion coefficient of the gas $\left(\mathrm{m}^{2} / \mathrm{s}\right)$.

The diffusion coefficient $D$ considering the molecular, viscous, and transient flows is expressed as follows [30]:

$$
\frac{1}{D}=\frac{1}{D_{v}}+\frac{1}{D_{m}} .
$$

By combining Eqs. (6)-(8), $D$ can be expressed as follows:

$$
D=\frac{D_{0} P_{m} k_{m}}{D_{0} \mu+P k_{m}} .
$$

Fig. 2 presents the relationship between the air diffusion and permeability coefficients ( $D$ and $k_{m}$, respectively) calculated using Eq. (9), assuming $P_{m}=100 \mathrm{kPa}, \mu=0.000018 \mathrm{~Pa} \cdot \mathrm{s}$, and $D_{0}=0.202 \times 10^{-4} \mathrm{~m}^{2} / \mathrm{s}$ (the diffusion coefficient between $\mathrm{N}_{2}$ and $\mathrm{O}_{2}$ at $20^{\circ} \mathrm{C}$ and the atmospheric pressure [31]). As shown, the curve of $D$ connects those of $D_{m}$ and $D_{v}$ smoothly.

As indicated by Eq. (7) and Fig. 2, $D_{v}$ remains constant. Conversely, when the viscous flow is dominant, the air permeability coefficient, i.e., $k_{v}\left(\mathrm{~m}^{2}\right)$, depends on the pore size and can be calculated using Eq. (10) [32].

$$
k_{v}=\frac{r^{2}}{8}
$$

The following equation was proposed [33] to correlate the air permeability and diffusion coefficients:

$$
k=\text { constant } \times D^{b},
$$

where $k$ is the air permeability coefficient. According to the theoretical derivations, $b=2$; however, $k$ agrees well with the experimental results at $b=1$. For deriving Eq. (11), Eq. (10) was used; therefore, the viscous flow was assumed implicitly. Fig. 3 shows the $k$ values calculated using Eq. (11) for $b=1$ and 2 with the $D$ curve in Fig. 2. The constants in Eq. (11) for $b=1$ and 2 were set as 200 and 25000, respectively. In Eq. (11), no distinction between the viscous and molecular flows is observed; therefore, their relationship is linear on a doublelogarithmic scale. As shown in Fig. $3, b=2$, which is a theoretically derived value, yields a slope that is different from those of the viscous and molecular flows derived using Eq. (9). Using $b=1$ results in a slope equal to that for the molecular flow, but this is a coincidence, because Eq. (11) is derived using Eq. (10), which assumes that the viscous flow is dominant.

Fig. 4 shows the relationship between the air permeability and diffusion coefficients for $D_{0}=0.160 \times 10^{-4} \mathrm{~m}^{2} / \mathrm{s}$ (diffusion coefficient between $\mathrm{CO}_{2}$ and air at $20^{\circ} \mathrm{C}$ and the atmospheric pressure [31]) and $0.202 \times 10^{-4} \mathrm{~m}^{2} / \mathrm{s}$ (diffusion coefficient between $\mathrm{N}_{2}$ and $\mathrm{O}_{2}$ at $20{ }^{\circ} \mathrm{C}$ and the atmospheric pressure [31]). These gas types correspond to the experimental conditions introduced in the next section. $P_{m}$ was set as 52 , 100 , and $225 \mathrm{kPa}$. Here, the pressures 52 and $225 \mathrm{kPa}$ correspond to the means of the atmospheric pressure and 3 $\mathrm{kPa}$ (initial absolute pressure obtained using the doublechamber method [7]) and $350 \mathrm{kPa}$ (highest absolute pressure obtained using the Cembureau method [34]), respectively. There was almost no difference between the $D_{0}$ values of $0.160 \times 10^{-4} \mathrm{~m}^{2} / \mathrm{s}$ and $0.202 \times 10^{-4} \mathrm{~m}^{2} / \mathrm{s}$, although a slight difference was observed in the region where the air permeability was higher than a few $10^{-16} \mathrm{~m}^{2}$. The diffusion test results for methane and air are discussed in the next section. The coefficient was $0.210 \times 10^{-4} \mathrm{~m}^{2} / \mathrm{s}$ [31]; this is almost identical to the data presented in Fig. 4. A change in $P_{m}$ shifted the curves horizontally.

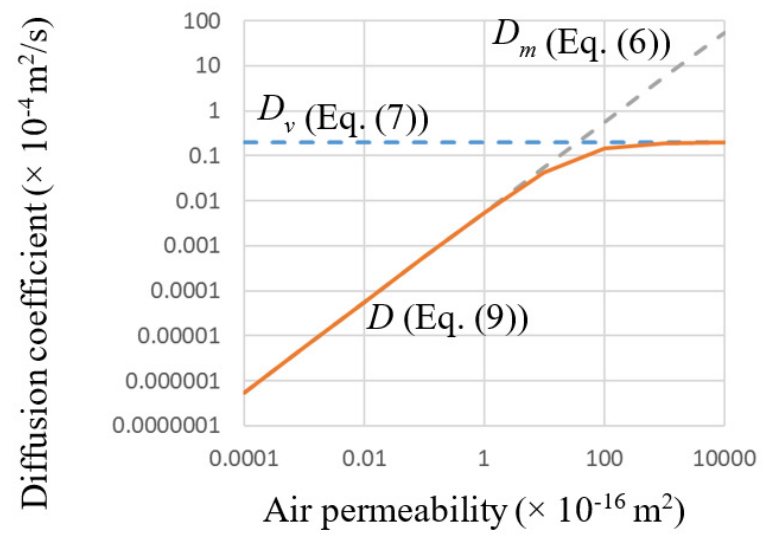

Figure 2. Relationship between the air diffusivity and air permeability described by Eqs. (6), (7), and (9).

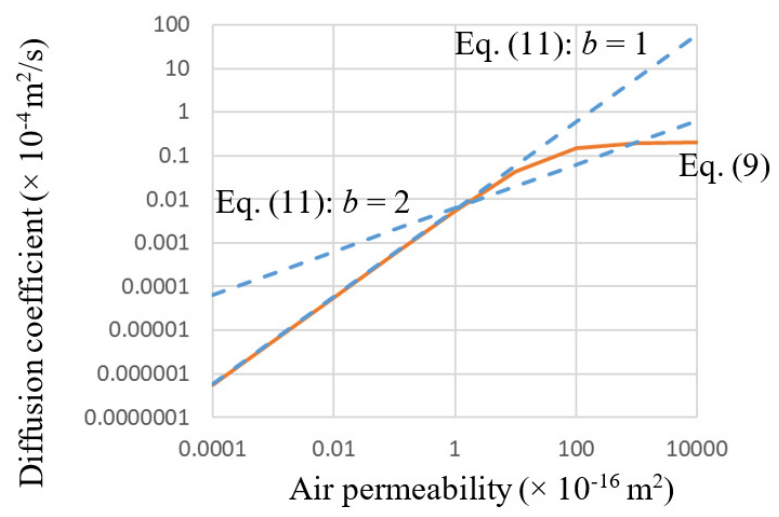

Figure 3. Relationship between the air diffusivity and permeability described by Eqs. (9) and (11). 
Table 1. Related works analysed in this study.

\begin{tabular}{|c|c|c|c|c|c|c|c|}
\hline \multirow{2}{*}{ Reference } & \multirow{2}{*}{ Specimen } & \multicolumn{2}{|c|}{ Diffusion test } & \multicolumn{4}{|c|}{ Permeability test } \\
\hline & & Gas 1 & Gas 2 & Gas & Monitor & Unit & Pressure $(\mathrm{kPa})$ \\
\hline$[16]$ & Concrete & $\mathrm{O}_{2}$ & $\mathrm{~N}_{2}$ & Air & Flow rate & $\mathrm{cm}^{4} /(\mathrm{s} \cdot \mathrm{N})$ & 200 \\
\hline [17] & Mortar & $\mathrm{CH}_{4}$ & Air & Air & Flow rate & $\mathrm{cm}^{2}$ & N/A \\
\hline [18] & Concrete & $\mathrm{O}_{2}$ & $\mathrm{~N}_{2}$ & Air & Pressure & $\mathrm{m}^{2}$ & 3 \\
\hline [19] & Paste & $\mathrm{CO}_{2}$ & Air & Air & Pressure & $\mathrm{m}^{2}$ & $150-250$ \\
\hline$[35]$ & Concrete & $\mathrm{O}_{2}$ & $\mathrm{~N}_{2}$ & Air & Flow rate & $\mathrm{cm}^{4} /(\mathrm{s} \cdot \mathrm{N})$ & 200 \\
\hline$[36]$ & Mortar & $\mathrm{O}_{2}$ & $\mathrm{~N}_{2}$ & $\mathrm{O}_{2}$ & Pressure & $\mathrm{m} / \mathrm{s}$ & $100 \rightarrow 50$ \\
\hline [37] & Concrete & $\mathrm{O}_{2}$ & $\mathrm{~N}_{2}$ & $\mathrm{O}_{2}$ & Pressure & $\mathrm{m} / \mathrm{s}$ & $100 \rightarrow$ Lower \\
\hline [38] & Mortar & $\mathrm{O}_{2}$ & $\mathrm{~N}_{2}$ & $\mathrm{O}_{2}$ & Flow rate & $\mathrm{m}^{2}$ & $50-250$ \\
\hline
\end{tabular}

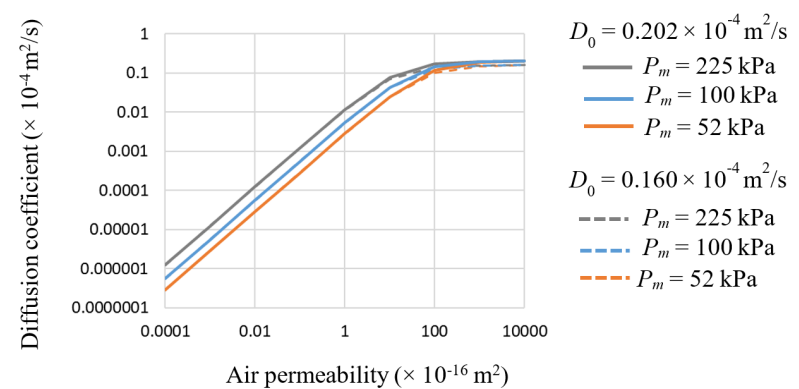

Figure 4. Relationship between the air diffusivity and permeability described by Eq. (9) with different values of $D_{0}$ and $P_{m}$.

\section{Data from previous studies}

Studies in which both the air diffusivity and permeability were measured were reviewed, as shown in Table 1. In the table, the materials, gases in the diffusion and permeability tests, units, and applied pressures in the permeability tests are presented. The units of the air diffusivity and permeability were converted to $\mathrm{cm}^{2} / \mathrm{s}$ and $\mathrm{m}^{2}$ when other units were used. When the reported air permeability value had a unit of $\mathrm{m} / \mathrm{s}$, it was multiplied by $\mu(0.000018 \mathrm{~Pa} \cdot \mathrm{s}) / \gamma\left(12.7 \mathrm{~N} / \mathrm{m}^{3}\right)$ to convert it to $\mathrm{m}^{2}$. When the reported air permeability value had a unit of $\mathrm{cm}^{4} /(\mathrm{s} \cdot \mathrm{N})$, it was multiplied by $10^{-4} \times \mu(0.000018 \mathrm{~Pa} \cdot \mathrm{s})$ to convert it to $\mathrm{m}^{2}$.

The equations for calculating air diffusivity and permeability were not the same in the studies analysed. However, the reported values were adopted 'as is' because the original data were not available; hence, it was impossible to calculate the air diffusivity and permeability using the same approach. Different equations have been used in previous studies for the pressure and flow rate, but these equations are similar because they are based on Darcy's law. In [17] and [35], for calculating the pressure difference, $\left(P_{1}^{2}-P_{2}^{2}\right) /\left(2 P_{2}\right)$ was used, which was also derived from Darcy's law. Here, $P_{1}$ represents the applied (input) pressure, and $P_{2}$ represents the output pressure (atmospheric pressure). However, in [16], $P_{1}-P_{2}$ was used. Assuming that the applied pressure was $250 \mathrm{kPa}$, the difference between the results of these equations was $70 \%$, which corresponded to a small difference on the logarithmic scale. In [18], a unique equation was used to calculate the diffusion coefficient for eliminating the effect of the sample thickness, because thin specimens typically exhibit smaller diffusion coefficients. The difference between the results for this equation and the conventional equation used in the literature was minimal, because sufficiently thick specimens were used in the previous studies.

In [16] and [35], fly ash and granulated blast furnace slag were used, respectively, and data for various moisture contents were presented. In [36], the samples were immersed in different aqueous solutions before drying, whereas in [37] and [38], the samples were conditioned at various humidity and temperature values.

In the measurement of the air permeability coefficient, it is difficult to determine the air permeability of the molecular flow $k_{m}$ because generally, the measured air permeability includes contributions from the viscous flow and transition flow. Therefore, in the conversion from the air permeability to the air diffusivity using Eq. (9), it is assumed that $k_{m}=k$, where $k$ is the total air permeability coefficient, which considers the viscous and molecular flows obtained in the actual measurements. According to this assumption, Eq. (9) is redefined as follows:

$$
D=\frac{D_{0} P_{m} k}{D_{0} \mu+P_{m} k} .
$$

\section{Results and discussion}

Fig. 5 presents the calculated and reported air diffusivity and permeability values. The reported data are distributed on two lines with different slopes; these data were obtained for 
concrete as well as mortar and cement paste. As shown, there was a strong correlation between the air diffusion and permeability coefficients for the cementitious materials. The calculated values were obtained assuming that $P_{m}=100 \mathrm{kPa}$, $\mu=0.000018 \mathrm{~Pa} \cdot \mathrm{s}$, and $D_{0}=0.202 \times 10^{-4} \mathrm{~m}^{2} / \mathrm{s}$ (diffusion coefficient between $\mathrm{N}_{2}$ and $\mathrm{O}_{2}$ at $20{ }^{\circ} \mathrm{C}$ and atmospheric pressure [31]). The effect of the gas type on $D_{0}$ was small, as shown in Fig. 4. $P_{m}$ was maintained at $100 \mathrm{kPa}$ to achieve better visibility (see Fig. 4 for the effect of $P_{m}$ ). The calculated and reported values exhibited good quantitative agreement, without the need for a correction factor. This indicates that Eq. (9) can describe the relationship between the diffusion coefficient and air permeability in cementitious materials. The calculated diffusion coefficients tended to be larger than the reported experimental results, with the differences increasing when the air permeability was approximately $1 \times 10^{-16} \mathrm{~m}^{2}$. The reasons for the differences may include the assumptions made in the calculation of the diffusion coefficients and air permeabilities and the experimental differences among the studies referenced. However, the main reason is the assumption made in the calculation of $D$ (that $k_{m}=k$ ). This is discussed later in the paper.

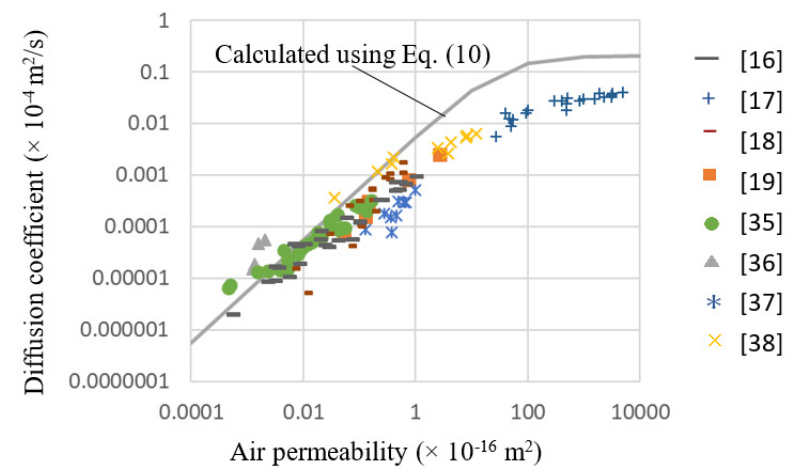

Figure 5. Relationship between the air diffusivity and permeability described by Eq. 10 with $P_{0}=100 \mathrm{kPa}$.

In the experiments, there was a point of a deviation from linearity at an air permeability of approximately $50 \times 10^{-16} \mathrm{~m}^{2}$. This indicates that the air permeability of $50 \times 10^{-16} \mathrm{~m}^{2}$ was the boundary between the molecular and viscous flows. Using Eq. 2, the mean free path at the atmospheric pressure $(P=100 \mathrm{kPa})$ was calculated as $62 \mathrm{~nm}$, assuming $T=293 \mathrm{~K}$ and $d=0.38 \mathrm{~nm}$ (diameter of a nitrogen molecule). Therefore, according to the thresholds described in Section 2, the viscous flow became dominant at $r>6200 \mathrm{~nm}$, and the molecular flow was dominant at $r<62 \mathrm{~nm}$. On the logarithmic scale, the midpoint of these radii was $620 \mathrm{~nm}$. This radius can be assumed as the boundary between the viscous and molecular flows. Therefore, when the measured air permeability was 50 $\times 10^{-16} \mathrm{~m}^{2}$, the representative pore radius in terms of the air penetration was $620 \mathrm{~nm}$. A relationship between the air permeability and the representative pore radius was empirically derived [23] as follows:

$$
r(\mathrm{~nm})=46 \sqrt{k\left(\times 10^{-16} m^{2}\right)} .
$$

According to Eq. (13), when $k=50 \times 10^{-16} \mathrm{~m}^{2}, r$ is $325 \mathrm{~nm}$, which is close to $620 \mathrm{~nm}$ on the logarithmic scale. This result validates the foregoing discussion and Eq. (13).

These calculations indicate that the largest difference between the calculation and measurement results occurred at the boundary of the molecular and viscous flows, and the main reason for this difference was the assumption of $k_{m}=k$, because when the air permeability is low, the molecular flow is dominant; thus, $k \cong k_{m}$. Conversely, when the air permeability is high, Eq. (12) becomes $D \cong D_{0}$. Therefore, the validity of the assumption that $k_{m}=k$ becomes questionable when the air permeability is moderate or when the transition flow is dominant.

As it is difficult to obtain $k_{m}$ from the air permeability tests, a parametric study is required. The calculated air diffusivity near the boundary can be varied by modifying Eq. (8) as follows:

$$
\frac{1}{D^{a}}=\frac{1}{D_{v}^{a}}+\frac{1}{D_{m}^{a}},
$$

where $a$ is a constant. The shape of the curve changes with respect to $a$, and the changes are largest near the boundary. By using Eq. (14) instead of Eq. (8), Eq. (12) is expressed as follows:

$$
D=\frac{D_{0} P_{m} k}{\sqrt[a]{\left(D_{0} \mu\right)^{a}+\left(P_{m} k\right)^{a}}} .
$$

Fig. 6 presents the curves with $a=0.15,0.25$, and 1 . As shown, $a=0.25$ yielded the best fit to the data for formulating the relationship between the diffusion coefficient and the air permeability with $k_{m}$ unknown and $k$ known.

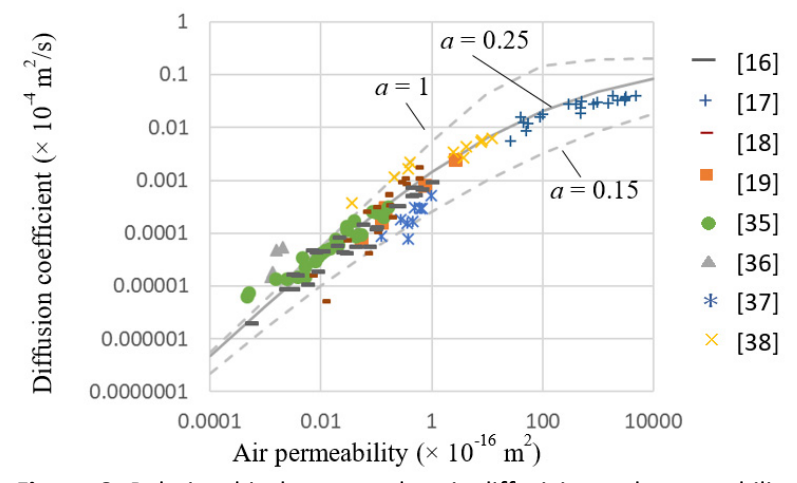

Figure 6. Relationship between the air diffusivity and permeability described by Eq. (15)

The consistency of the results in Fig. 6 validates the conversion of the air permeability into the diffusion coefficient using Eq. (15), even though it was difficult to obtain $k_{m}$ in the actual measurements. As introduced previously, devices that can evaluate the air permeability of concrete in a non-destructive manner are presently available, and it is possible to obtain the diffusion coefficient of concrete onsite using such devices and Eq. (15). Furthermore, Fig. 6 indicates that it is not necessary to evaluate both the air diffusivity and permeability, because either one can be obtained by converting the other. The results of this study will contribute 
to the rational evaluation of the durability of concrete structures.

Fig. 7 shows the curves for $D_{0}=0.160 \times 10^{-4} \mathrm{~m}^{2} / \mathrm{s}$ (diffusion coefficient between $\mathrm{CO}_{2}$ and air) at $P_{m}=52$ (mean pressure obtained using the double-chamber method [7]), 100, and $225 \mathrm{kPa}$ (highest mean pressure determined using the Cembureau method [34]); these curves were obtained using Eq. (15) and $a=0.25$. This relationship can be used to convert the air permeability into the diffusivity of $\mathrm{CO}_{2}$ and $\mathrm{O}_{2}$ molecules in air $\left(\mathrm{N}_{2}\right)$ because the $D_{0}$ of these gases did not change significantly (Fig. 4). $\mathrm{N}_{2}$ and air are compatible, as the diffusion coefficients of $\mathrm{CO}_{2}$ vs. $\mathrm{N}_{2}$ and $\mathrm{CO}_{2}$ vs. air are $0.16 \times$ $10^{-4} \mathrm{~m}^{2} / \mathrm{s}$ [31].

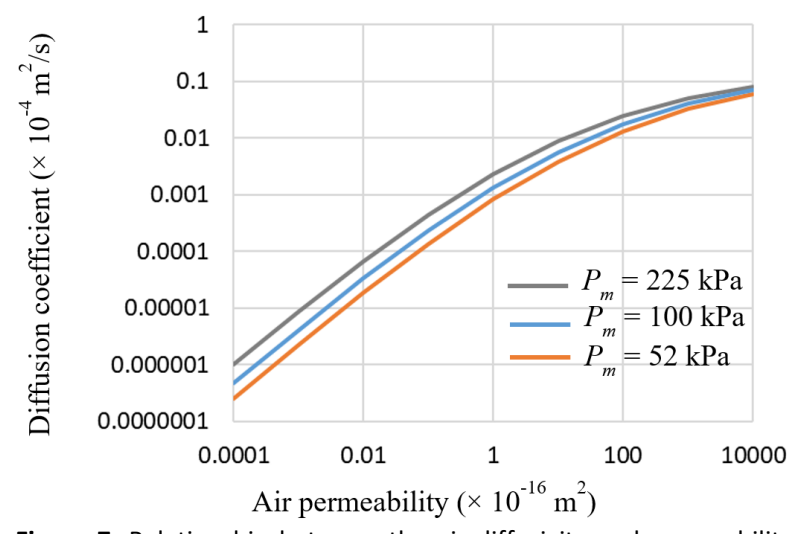

Figure 7. Relationship between the air diffusivity and permeability described by Eq. (15) with $a=0.25$ and $D_{0}=0.160 \times 10^{-4} \mathrm{~m}^{2} / \mathrm{s}$.

\section{Conclusions}

In this study, the relationship between the air diffusivity and permeability was investigated via a theoretical approach and literature survey. An equation for the relationship between the air diffusivity and permeability in molecular, transition, and viscous flows was derived. Although a straight circular tube was assumed in the derivation of the equation, the calculated values exhibited good quantitative agreement with experimental data. This indicates that the air diffusion and permeability are governed by the same factors (possibly the pore structure). The air diffusion coefficient can be converted into the permeability coefficient (and vice versa) using the equation derived in this paper. The analysed studies provided data for concrete, mortar, and cement paste of various mix designs prepared under various conditions; however, further tests of samples prepared under extreme conditions are needed to determine the limitations of the equation derived in this paper.

\section{Acknowledgements}

This study was supported by JSPS KAKENHI (grant number 18K13809).

\section{Conflicts of interest}

There are no conflicts of interest to declare.

\section{References}

[1] AM. Neville, Properties of Concrete 5th Edition. Trans-Atlantic Publications, Inc (2012).

[2] K. Kobayashi, K. Shuttoh, Oxygen diffusivity of various cementitious materials. Cem Concr Res (1991) 21(2): 273-284. https://doi.org/10.1016/0008-8846(91)90009-7

[3] YF. Houst, FH. Wittmann, Influence of porosity and water content on the diffusivity of $\mathrm{CO} 2$ and $\mathrm{O} 2$ through hydrated cement paste. Cem Concr Res (1994) 24(6): 1165-1176. https://doi.org/10.1016/0008-8846(94)90040-X

[4] RK. Dhir, PC. Hewlett, YN. Chan, Near surface characteristics of concrete: intrinsic permeability. Mag Concr Res (1989) 41(147): 87 97. https://doi.org/10.1680/macr.1989.41.147.87

[5] JJ. Kollek, The determination of the permeability of concrete to oxygen by the Cembureau method-a recommendation. Mater Struct (1989) 22(3): 225-230. https://doi.org/10.1007/BF02472192

[6] RILEM TC 116-PCD, Permeability of concrete as a criterion of its durability. Mater Struct (1999) 32: 174-179.

[7] RJ. Torrent, A two-chamber vacuum cell for measuring the coefficient of permeability to air of the concrete cover on site. Mater Struct (1992) 25(6): 358-365. https://doi.org/10.1007/BF02472595

[8] RK. Dhir, PC. Hewlett, EA. Byars, IG. Shaaban, A new technique for measuring the air permeability of near-surface concrete. Mag Concr Res (1995) 47(171): 167-176. https://doi.org/10.1680/macr.1995.47.171.167

[9] PA. Claisse, E. Ganjian, TA. Adham, A vacuum-air permeability test for in situ assessment of cover concrete. Cem Concr Res (2003) 33(1): 47 53. https://doi.org/10.1016/S0008-8846(02)00912-2

[10] P. Paulini, A laboratory and on-site test method for air permeability of concrete, 2nd International Symposium on Service Life Design for Infrastructure, Delft, The Netherlands (2010) 995-1002.

[11] A. Nonaka, N. Yuasa, Rapid testing method for air permeability of structural concrete using drilled hole. J Struct Constr Eng (Transactions of AIJ) (2014) 79(700): 689-696. https://doi.org/10.3130/aijs.79.689

[12] K.Yang, P.A.M. Basheer, Y. Bai, B.J. Magee A.E.Long, Development of a new in situ test method to measure the air permeability of high performance concretes. NDT \& E International (2014) 64: 30-40. https://doi.org/10.1016/j.ndteint.2014.02.005

[13] B.G. Salvoldi, H. Beushausen, M.G. Alexander, Oxygen permeability of concrete and its relation to carbonation. Constr Build Mater (2015) 85:30-37. https://doi.org/10.1016/i.conbuildmat.2015.02.019

[14] Y. Sakai, C. Nakamura, T. Kishi, TH. Ahn, Interpretation of nondestructive test results for evaluation of mass transfer resistance of concrete members. the 5th International Conference of ACF (2012).

[15] Y. Sakai, C. Nakamura T. Kishi, Correlation between permeability of concrete and threshold pore size obtained with epoxy-coated sample. J Adv Concr Technol (2013) 11(8): 189-195. https://doi.org/10.3151/jact.11.189

[16] H. Iwasawa, I. Ujike, S. Nagataki, Study of relation between air permeability coefficient and oxygen diffusion coefficient of concrete. Annual Conference of Japan Society of Civil Engineers (1990) 764-765 (in Japanese).

[17] K. Sasaki, H. Miyakoshi, Air and water permeabilities of coal ash and portland cement mortars. Scientific and technical reports of the Mining College, Akita University (1992) 13:1-8 (in Japanese).

[18] T. Toyofuku, T. Shirakawa, T. Sato, Non-destructive testing for evaluation of concrete structures. Kyugikyo (2009) (in Japanese).

[19] K. Namoulniara, P. Turcry, A. Aït-Mokhtar, Measurement of CO2 effective diffusion coefficient of cementitious materials. European $J$ Env Civ Eng (2016) 20(10): 1183-1196. https://doi.org/10.1080/19648189.2015.1132011

[20] Y. Sakai, Relationship between pore structure and chloride diffusion in cementitious materials. Constr Build Mater (2019) 229: 116868. https://doi.org/10.1016/i.conbuildmat.2019.116868

[21] Y. Sakai, Correlations between air permeability coefficients and pore structure indicators of cementitious materials. Constr Build Mater (2019) 209: 541-547. https://doi.org/10.1016/j.conbuildmat.2019.03.068

[22] Y. Sakai, Relationship between water permeability and pore structure of cementitious materials. Mag Concr Res 2019 (in print). https://doi.org/10.20944/preprints201812.0073.v1

[23] Y. Sakai, C. Nakamura, T. Kishi, Evaluation of mass transfer resistance of concrete based on representative pore size of permeation resistance. Constr Build Mater (2014) 51: 40-46. https://doi.org/10.1016/j.conbuildmat.2013.10.037 
[24] A. Chambers, RK. Fitch, BS. Halliday, Basic vacuum technology. IOP Publishing (1998). https://doi.org/10.1201/NOE0750304955

[25] M. Pirani, J. Yarwood, Principles of vacuum engineering. Chapman and Hall (1961)

[26] JF. O'Hanhon, A user's guide to vacuum technology. John Wiley \& Sons (2003).

[27] H. Kumagai, G. Tominaga, Y. Tuzi, G. Horikoshi, Vacuum science and engineering. Shokabo (2012) (in Japanese).

[28] Y. Sakai, T. Kishi, Numerical simulation of air permeability in covercrete assuming molecular flow in circular tubes. Constr Build Mater (2016) 125: 784-789.

https://doi.org/10.1016/j.conbuildmat.2016.08.105

[29] Y. Sakai, Numerical study on the relationship among air permeability, pore size and pressure assuming molecular and viscous flows. J Adv Concr Technol (2017), 15(3): 103-109. https://doi.org/10.3151/jact.15.103

[30] P. Schneider, D. Gelbin, Direct transport parameters measurement versus their estimation from mercury penetration in porous solids. Chem Eng Sci (1985) 40(7): 1093-1099. https://doi.org/10.1016/0009-2509(85)85067-3

[31] WM. Haynes, Handbook of chemistry and physics, CRC Press, (2012).

[32] SJ. Glass, DJ. Green, Permeability and infiltration of partially sintered ceramics, J Amer Ceram Soc (1999) 82(10): 2745-2752. https://doi.org/10.1111/j.1151-2916.1999.tb02151.x

[33] LO. Nilsson, T. Luping, Chapter 3 - Relations between different transport parameters. In J. Kropp \& H.K. Hilsdorf, eds. Performance criteria for concrete durability. RILEM (1995): 15-32.

[34] JJ. Kollek, The determination of the permeability of concrete to oxygen by the Cembureau method-a recommendation. Mater Struct (1989) 22(3): 225-230. https://doi.org/10.1007/BF02472192

[35] I. Ujike, M. Narazaki, S. Nagataki, A study on relationship between air permeability and diffusions of oxygen and of chloride ions. Paper presented at the Proceedings of Japan Concrete Institute. 1993.

[36] C. Villani, TE. Nantung, WJ. Weiss, The influence of deicing salt exposure on the gas transport in cementitious materials. Constr Build Mater (2014) 67: 108-114.

https://doi.org/10.1016/j.conbuildmat.2013.08.018

[37] C. Peretti, A. Leemann, R. Loser, P. Lura, Influence of different conditioning regimes on the oxygen diffusion and oxygen permeability of concrete. Paper presented at the 2nd International Conference on Microstructural-Related Durability of Cementitious Composites, Amsterdam, The Netherlands 2012.

[38] HS. Wong, NR. Buenfeld, MK. Head, Estimating transport properties of mortars using image analysis on backscattered electron images. Cem Concr Res (2006) 36(8): 1556-1566.

https://doi.org/10.1016/i.cemconres.2006.05.002 